\title{
Relokasi Gempa Utama dan Susulan Mentawai 7,8Mw dan Implikasinya terhadap Seismotektonik Sumatra
}

\author{
Arya Dwi Candra* dan Bagus Jaya Santosa \\ Jurusan Fisika, Fakultas Matematika dan Ilmu Pengetahuan Alam, \\ Institut Teknologi Sepuluh Nopember (ITS), Kampus ITS Sukolilo, Surabaya 60111
}

Intisari

\begin{abstract}
Sumatera merupakan salah satu pulau yang mempunyai aktivitas tektonik tinggi yang disebabkan oleh adanya zona tektonik di sekitar wilayah Sumatra. Sesar Mentawai merupakan salah satu zona tektonik yang sering menimbulkan aktivitas gempa kuat. Salah satunya adalah gempa Mentawai 25 Oktober 2010 yang mengguncang wilayah Sumatra dengan kekuatan 7,8Mw. Pada penelitian ini di gunakan program HYPO71 untuk meningkatkan akurasi posisi hiposenter. Data yang digunakan adalah data gempa utama dan gempa susulan yang terjadi pada tanggal 25 oktober 2010. Rekaman seismogram dalam tiga komponen dari gempa-gempa yang dianalisis, meliputi dua komponen horizontal (-E, -N) dan satu komponen vertikal (-Z) pada stasiunstasiun observasi seismik di sekitar hiposenter gempa. Proses persiapan pengolahan data awalmeliputi koreksi instrumen, merotasi ke dalam koordinat radial dan transversal serta penyelarasan waktu asal gempa. Data arrival time gelombang P dan S dari hasil pencuplikan seismogram digunakan sebagai input untuk program HYPO71. Hasil relokasi gempa dengan menggunakan HYPO71 menunjukkan bahwa lokasi hiposenter memiliki sebaran yang lebih fokus daripada sebaran hiposenter sebelum relokasi. Hal dapat menjelaskan adanya koherensi antara posisi hiposenter gempa susulan dengan kondisi geologi di megathrust dan sesar Mentawai. Gempa susulan yang terjadi kemungkinan disebabkan oleh proses ruptur di sesar Mentawai yang dipicu oleh gempa utama.
\end{abstract}

\begin{abstract}
Sumatra is one of the islands that has high tectonic activity which is caused by tectonic zones around it. Mentawai fault is one of the tectonic zones that often leads to strong seismic activity. One of them was October 25, 2010 Mentawai earthquake that rocked Sumatra with 7,8Mw strength. This study used HYPO71 program to improve the accuracy of hypocenter position. The data used in this study are a mainshock and aftershocks earthquake data that occurred on October 25, 2010. Seismogram recorded in three components from earthquake events analyzed, they are the two horizontal components (-E, -N) and a vertical component (-Z) from seismic obeservation station around the hypocenter. Process of raw data preparation includes instrument correction, rotating into radial and transverse coordinates and time alignment of the earthquake origin time. Arrival time data of $\mathrm{P}$ and $\mathrm{S}$ wave from seismograms picking results used as input to the HYPO71 program. The result of the earthquake relocation using HYPO71 shows that the location of the hypocenters havemore focus distribution than the hypocenter distribution prior to relocation. It may explain the absence of coherence between aftershock hypocentersposition with geological conditions of megathrust and Mentawai fault. Aftershocks that occurred may be due to the rupture in the Mentawai fault which was triggered by a mainshock.
\end{abstract}

KATA KUNCI: Earthquake relocation, HYPO71, Mentawai earthquake, Megathrust

\section{PENDAHULUAN}

Pulau Sumatra merupakan salah satu bagian dari kepulauan Indonesia yang memiliki kondisi geologi yang unik karena berada pada daerah tumbukan dua lempeng besar, yaitu lempeng Indo-Australia di bagian selatan dan lempeng Eurasia di bagian utara. Pertemuan dua lempeng ini menyebabkan wilayah ini menjadi salah satu tempat dengan gejala seismik yang paling aktif di dunia. Hal ini menyebabkan Sumatra menjadi wilayah yang paling ideal untuk mempelajari gejala gempa bumi.
Lempeng Indo-Australia mendorong lempeng Eurasia ke arah Utara-Timur laut. Tingkat konvergensi lempeng sebesar $\approx 60-\mathrm{mm} /$ th dan bergerak tegak lurus ke muka subduksi di dekat Jawa, yang berkurang hingga $52 \mathrm{~mm} /$ th di Sumatera Utara dengan arah miring sekitar $40^{\circ}$ dan menjadi dominan di sebelah utara dari pulau Nicobar [1]. Selama ratusan tahun, interfase dari megathrust (lapisan yang mempertemukan dua lempeng tektonik dimana sering terjadi aktivitas tektonik) tetap terkunci, dengan demikian pergerakan relatif dari kedua lempeng tersebut menyebabkan peningkatan akumulasi energi di sekitar interfase. Apabila akumulasi energi sudah melebihi batas elastisitas batuan, maka akan terjadi ruptur dan gerakan tiba-tiba (lurch) sehingga dapat menimbulkan terjadinya gempa besar dan tsunami. 
TABEL I: Lokasi dan waktu terjadinya gempa pada tanggal 25 oktober 2010

\begin{tabular}{lccccc}
\hline \hline Event & Lat & Long & Depth & Magnitude & Time \\
\hline 1 & $-3,46$ & 100,20 & 12 & 7,8 & $14: 42: 21$ \\
2 & $-3,44$ & 100,01 & 12 & 5 & $15: 10: 00$ \\
3 & $-3,43$ & 99,89 & 19 & 5,2 & $15: 21: 11$ \\
4 & $-2,96$ & 100,37 & 22 & 6,1 & $19: 37: 30$ \\
5 & $-2,80$ & 100,04 & 26 & 5 & $22: 10: 04$ \\
6 & $-3,29$ & 100,46 & 25 & 6 & $22: 59: 54$ \\
\hline \hline
\end{tabular}

Gempa besar yang disertai tsunami di Sumatera telah terjadi sejak tahun 1797, 1833 dan 1861. Kemudian terjadi kembali mulai tahun 2000 (Lampung), 2004 (Aceh), 2005 (Nias), 2007 (Bengkulu). Di sepanjang jalur subduksiterdapat seismik gap pada segmen Mentawai. Hal ini mengindikasikan bahwa wilayah megathrust di depan busur Sumatera bagian barat memiliki potensi terjadinya gempa besar dan tsunami. Konca et al. [2] berpendapat bahwapada serangkaian gempa 2007 hanya energi parsial yang telah dilepaskan sehingga gempa besar dari segmen Mentawai dapat terjadi dalam waktu yang relatif sangat dekat.Pada tanggal 30 September 2009 telah terjadi gempa di Padang dengan kekuatan 7,6 Mw, tetapi tidak merobek lapisan zona subduksi dan tidak mengurangi akumulasi stress pada megathrust segmen Mentawai secara signifikan [3]. Hal ini menunjukkan bahwa belum terjadi pelepasan energi yang terakumulasi seluruhnya sehingga energi pada segmen Mentawai tetap tinggi dan dapat memicu munculnya gempa besar di masa yang akan datang.

Gempa Mentawai 25 Oktober 2010 adalah gempa tektonik kuat yang mengguncang wilayah Sumatra. Stasiun-stasiun observasi milik jaringan GFZ (Geo Forschungs Zentrum) digunakan untuk menentukan letak koordinat hiposenter gempa, yakni berada pada $-3,46^{\circ} \mathrm{LS}$ dan $100,20^{\circ}$ BT pada kedalaman sumber $12 \mathrm{~km}$ dan magnitude 7,8 Mw. Pada penentuan posisi hiposenter gempa, akurasi posisi sangat dipengaruhi beberapa faktor, diantaranya: geometri jaringan, fase gelombang yang digunakan, ketelitian pembacaan arrival time dan model struktur kecepatan bumi. Penentuan hiposenter yang akurat dan konsisten merupakan kebutuhan mutlak untuk analisis kegempaan lebih lanjut. Oleh karena itu dibutuhkan teknik relokasi gempabumi yang mampu menghasilkan lokasi hiposenter gempa dengan lebih akurat daripada data hiposenter real-time. Pada penelitian ini di gunakan program HYPO71 [4] untuk meningkatkan akurasi posisi hiposenter.

\section{METODE PENELITIAN}

Digunakan data hiposenter yang diperoleh dari GFZ yaitu enam gempa yang terjadi pada tanggal 25 oktober 2010 di bagian barat Sumatra, seperti ditunjukkan pada Gambar 1. Sedangkan lokasi serta waktu terjadinya gempa disajikan dalam Tabel I. Data seismogram diperoleh dari stasiun observatorium kegempaan GFZ disekitar hiposenter gempagempa yang diamati. Didapatkan rekaman data gempa dalam tiga komponen, meliputi dua komponen horizontal (-E, -N)

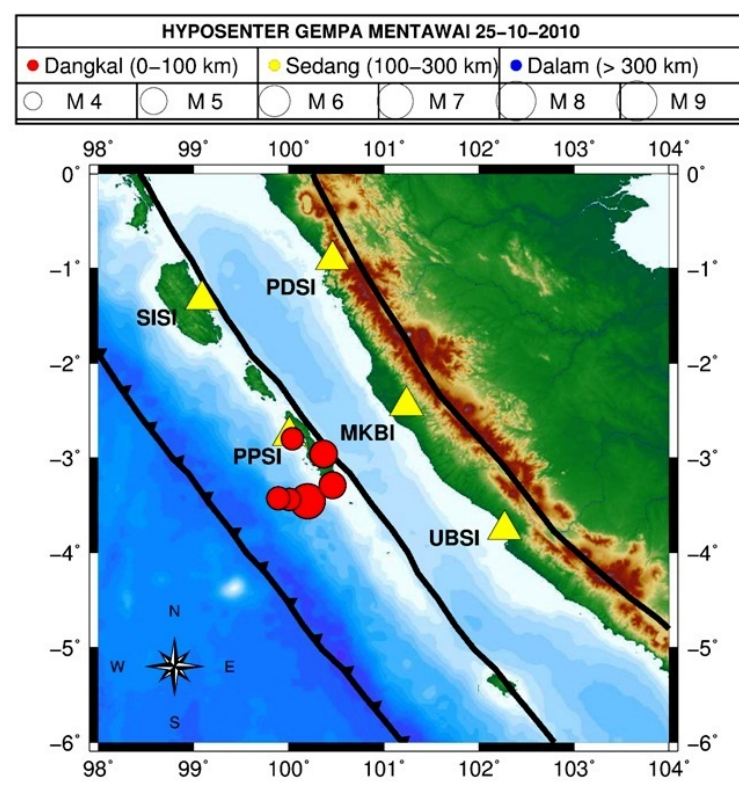

Gambar 1: Persebaran hiposenter gempa utama dan susulan Mentawai 25 oktober 2010 beserta stasiun pencatat gempa yang digunakan dalam penelitian.

dan satu komponen vertikal (-Z). Data seismik 3 komponen tersebut kemudian dilakukan pengolahan data awal yaitu berupa koreksi instrumen, rotasi ke dalam koordinat radial dan transversal serta penyelarasan waktu asal gempa (origin align).

Koreksi instrumen dianggap sebagai langkah pengolahan yang paling mendasar dalam seismologi karena berkaitan dengan pengamatan data mentah sehingga penting untuk dilakukan oleh para seismolog [5]. Koreksi instrumen digunakan untuk mengubah data seismogram yang berbasis tegangan menjadi data seismogram berbasis pergeseran tanah (displacement). Hal ini dilakukan untuk mendapatkan visual pergeseran tanah yang sebenarnya akibat dari gempa bumi. Dilakukan juga rotasi koordinat dari ENZ menjadi koordinat RTZ. Hasil rotasi berupa data primer yang akan dianalisis, yaitu data dengan komponen -R, -T, -Z. Pada perhitungan waktu terjadinya event gempa, terdapat perbedaan waktu origin terjadinya gempa dengan waktu origin gempa di tiap stasiun sehingga perlu dilakukan koreksi penyelarasan waktu origin terjadinya gempa. Kemudian data dianalisis untuk mendapatkan arrival time gelombang $\mathrm{P}$ dan $\mathrm{S}$. Gelombang P diindikasikan sebagai usikan pertama yang terekam dalam seismogram, sedangkan gelombang S diketahui dari perubahan fase gelombang $\mathrm{P}$, dan selalu berada sebelum gelombang permukaan. Model struktur kecepatan bumi yang digunakan pada penelitian adalah kombinasi antara model bumi Haslinger [6] dan Santosa [7]. Kasmolan [8] menyatakan bahwa model bumi ini adalah model bumi yang paling relevan untuk pulau Sumatera.

Data arrival time merupakan data penting yang harus dimiliki, dan semuanya dikonversi ke dalam detik. Digunakan program HYPO71 untuk melakukan relokasi hiposenter. Pro- 
(a)
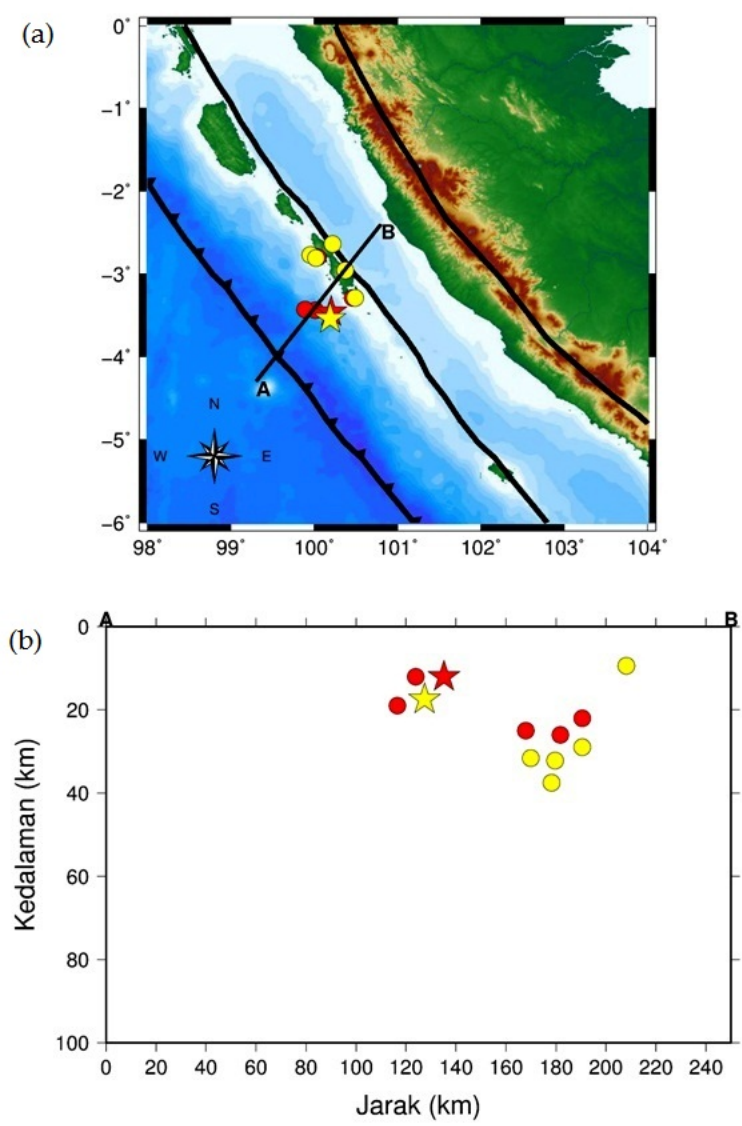

Gambar 2: Hasil cross section relokasi gempa, (a) hasil relokasi episenter, (b) hasil relokasi hyposenter (simbol bintang menunjukkan gempa utama, simbol lingkaran menunjukkan gempa susulan, warna merah menunjukkan gempa sebelum direlokasi, warna kuning menunjukkan gempa setelah relokasi).

gram HYPO71 membutuhkan informasi lokasi stasiun, model kecepatan seismik pada kerak, dan informasi fase pada file input. Proses selanjutnya adalah mengasumsikan trial origin time dan lokasi hiposenter untuk gempa, dan mengoptimalkan origin time dan lokasi hiposenter dengan iterasi meminimalkan least square error dari waktu tempuh yang dihitung dari stasiun masukan, model kecepatan dan informasi fase. Diperlukan input arrival time gelombang $\mathrm{P}$ dan gelombang S. Program HYPO71 memberikan keluaran berupa lokasi hiposenter baru. Output dari HYPO71 digambarkan ke dalam petatopografi menggunakan Generic Mapping Tools (GMT)[9].

\section{HASIL DAN PEMBAHASAN}

Gempa Mentawai pada tanggal 25 oktober 2010 merupakan jenis gempa dangkal, yaitu berada pada kedalaman kurang dari $100 \mathrm{~km}$. Hasil dari relokasi hiposenter menggunakan program HYPO71 memberikan posisi hiposenter yang berbeda dengan posisi hiposenter sebelum dilakukan relokasi, seperti disajikan pada Tabel II.
TABEL II: Perbandingan hasil penentuan hiposenter.

\begin{tabular}{lcccccccc}
\hline \hline Time & \multicolumn{4}{c}{ GFZ } & \multicolumn{4}{c}{ HYPO71 } \\
& Lat & Long & Depth & Lat & Long & Depth & Rms \\
\hline $14: 42: 21$ & $-3,46$ & 100,20 & 12 & $-3,54$ & 100,19 & 17,4 & 0,17 \\
15:10:00 & $-3,44$ & 100,01 & 12 & $-2,64$ & 100,22 & 9,44 & 0,66 \\
$15: 21: 11$ & $-3,43$ & 99,89 & 19 & $-2,77$ & 99,95 & 37,8 & 0,45 \\
$19: 37: 30$ & $-2,96$ & 100,37 & 22 & $-2,96$ & 100,37 & 28,9 & 0,2 \\
$22: 10: 04$ & $-2,80$ & 100,04 & 26 & $-2,81$ & 100,02 & 32,1 & 0,9 \\
22:59:54 & $-3,29$ & 100,46 & 25 & $-3,29$ & 100,49 & 31,6 & 0,14 \\
\hline \hline
\end{tabular}

Berdasarkan hasil relokasi dengan menggunakan HYPO71 diperoleh perbedaan posisi hiposenter sebelum dan sesudah relokasi. Perubahan paling signifikan adalah pada kedalaman gempa sebelum dan setelah dilakukan relokasi. Sebelum dilakukan relokasi, posisi hiposenter gempa rata-rata memiliki kedalaman 19,3 km, sedangkan setelah dilakukan relokasi mendapatkan hasil kedalaman gempa rata-rata menjadi 26,17. Adanya perbedaan hiposenter dapat dijadikan acuan dalam melakukan interpretasi zona patahan atau zona subduksi melalui tren posisi hiposenterjika dilihat secara vertikal [10]. Berdasar persebaran gempa yang tampak secara vertikal dapat digunakan untuk mendeskripsikan kluster yang menandakan adanya zona patahan atau subduksi di daerah tersebut [11]. Sebaran posisi hiposenter setelah dilakukan relokasi menunjukkan kondisi yang sesuai dengan kondisi geologi daerah tersebut, dimana sebagian gempa hasil relokasi berada di megathrust dan di sesar Mentawai. Gambar 3 merupakan hasil penelitian Singh et al. [12] yang menggambarkan bahwa di segmen Mentawai terdapat backthrust aktif yang berperan dalam aktivitas seismik di daerah tersebut. Berdasarkan Gambar 2 dan Gambar 3 dapat dilihat bahwa terdapat koherensi posisi hiposenter hasil relokasi dengan tren dari megathrust dan sesar Mentawai.

Gambar 4 merupakan mekanisme fokal yang diperoleh dari observatorium IRIS yang menunjukkan bahwa gempa utama dan susulan yang terjadi di Mentawai memiliki orientasi reverse. Hal ini selaras dengan tren dari hiposenter gempa hasil relokasi dimana posisi gempa susulan berada di sesar Mentawai. Adanya kesesuaian antara hiposenter hasil relokasi dengan tren sesar Mentawai mengindikasikan bahwa gempa susulan yang terjadi diperkirakan sebagai akibat dari adanya proses ruptur pada sesar Mentawai yang disebabkan oleh gempa utama.

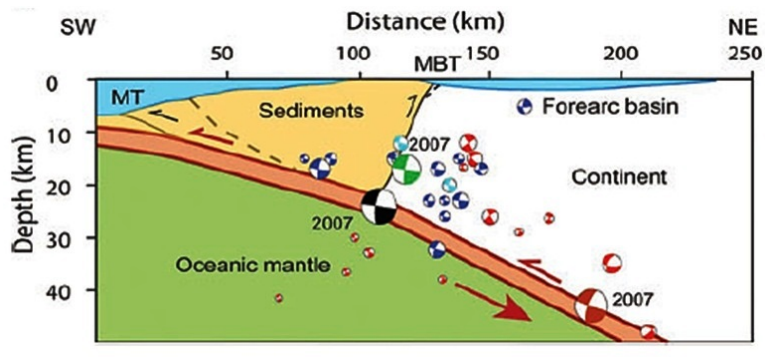

Gambar 3: Permodelan skematik zona subduksi dan sesar Mentawai [12] 


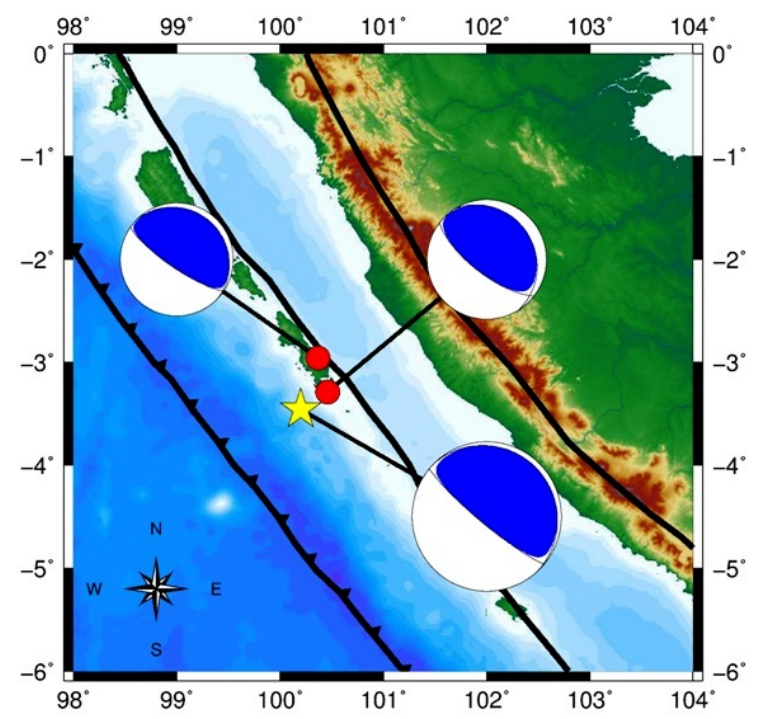

Gambar 4: Mekanisme fokal dari gempa Mentawai 25 oktober 2010, diambil melalui IRIS.

Hasil perhitungan inversi dengan menggunakan HYPO71 diperoleh nilai RMS (Root Mean Squares) yang bervariasi antara 0,02-0,9. Nilai RMS menunjukkan nilai keakuratan dari parameter model yang diperoleh. Ketika nilai RMS ke- cil maka nilai parameter model yang dihasilkan mendekati keadaan yang sebenarnya. Dari hasil RMS rata-rata diperoleh nilai 0,42 sehingga dapat dikatakan bahwa hasil relokasi dengan menggunakan HYPO71 memberikan hasil yang baik.

\section{SIMPULAN}

Hasil relokasi hiposenter gempa utama dan gempa susulan Mentawai 25 oktober 2010 mengalami pergeseran distibusi hiposenter lebih terpusat di sekitar sesar Mentawai. Hal ini menunjukkan adanya koherensi antara tren hiposenter gempa susulan dengan kondisi geologi dari megathrust dan sesar Mentawai. Gempa susulan yang terjadi diperkirakan sebagai akibat dari proses ruptur yang muncul di sesar Mentawai akibat gempa utama.

\section{Ucapan Terima Kasih}

Penulis pertama mengucapkan terimakasih kepada Direktorat Jendaral Pendidikan Tinggi, Departemen Pendidikan dan Kebudayaan Republik Indonesia yang telah memberikan bantuan dana melalui Beasiswa Pendidikan Pascasarjana Dalam Negeri (BPPDN) 2013.
[1] L. Prawirodirdjo, and Y. Bock, J. Geophys. Res., 109(B8), B08405 (2004).

[2] A.O. Konca, et al., Nature, 456(7222), 631-635 (2008).

[3] J. McCloskey, et al., Nature Geosci, 3(2), 70-71 (2010).

[4] W.H.K. Lee, and J.C. Lahr, Hypo71 (Revised): A Computer Program For Determining Hypocenter Magnitudo and First Motion Pattern of Local Earthquakes, US Departement of The Geology Survey National Center for Earthquake Center, 1972.

[5] M.M. Haney, et al., Seismological Research Letters, 83(5), 834845 (2012).

[6] F. Haslinger, et al., Tectonophysics, 304(3), 201-218 (1999).

[7] B.J. Santosa, Analyzing the seismogram of earthquakes on
Sumatra-Java Subduction plane at CHTO observation station, Jurnal MIPA Unlam, 13, 13-21 (2008).

[8] M. Kasmolan, et al., Cent. Eur. J. Geosci., 2(4), 455-474 (2010),

[9] P. Wessel, and W.H.F. Smith, Eos Trans. AGU, 79(47), 579-579 (1998).

[10] F. Hirose, J. Nakajima, and A. Hasegawa, J. Geophys. Res., 113(B9), B09315 (2008).

[11] M. Ishida and A. H. Hasemi, J. Geophys. Res., 93(B3), 20762094 (1988).

[12] S.C. Singh, et al., Geophysical Journal International, 180(2), 703-714 (2010). 